\title{
Strength properties of fly ash stabilized mixes
}

Dimter, Sanja; Rukavina, Tatjana; Dragčević, Vesna

Source / Izvornik: Road Materials and Pavement Design, 2011, 12, 687 - 697

Journal article, Published version

Rad u časopisu, Objavljena verzija rada (izdavačev PDF)

https://doi.org/10.1080/14680629.2011.9695266

Permanent link / Trajna poveznica: https://urn.nsk.hr/urn:nbn:hr:133:586597

Rights / Prava: Attribution-NonCommercial-NoDerivatives 4.0 International/ImenovanjeNekomercijalno-Bez prerada 4.0 međunarodna

Download date / Datum preuzimanja: 2023-04-26

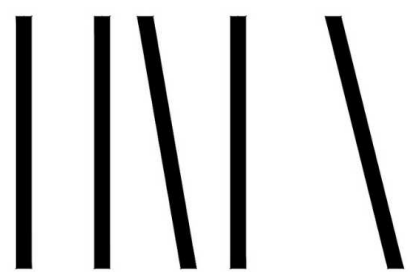

GRADEVINSKI I ARHITEKTONSKI FAKULTET OSIJEK Faculty of Civil Engineering and Architecture Osijek

\section{Repository / Repozitorij:}

Repository GrAFOS - Repository of Faculty of Civil

Engineering and Architecture Osijek
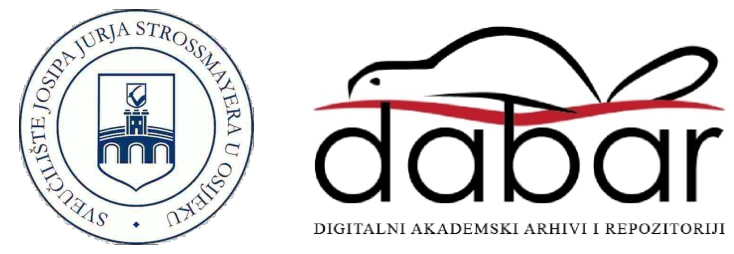


\section{Strength Properties of Fly Ash Stabilized Mixes}

\section{Sanja Dimter , Tatjana Rukavina \& Vesna Drag[cbreve]ević}

To cite this article: Sanja Dimter, Tatjana Rukavina \& Vesna Drag[cbreve]ević (2011) Strength Properties of Fly Ash Stabilized Mixes, Road Materials and Pavement Design, 12:3, 687-697, DOI: 10.1080/14680629.2011.9695266

To link to this article: https://doi.org/10.1080/14680629.2011.9695266

\section{册 Published online: 17 Oct 2011.}

Submit your article to this journal ๘

Џ Article views: 144

Q View related articles ¿

Citing articles: 5 View citing articles ๘ 


\title{
Strength Properties of Fly Ash Stabilized Mixes
}

\author{
Sanja Dimter* — Tatjana Rukavina** — Vesna Dragčević** \\ * Faculty of Civil Engineering \\ University of Osijek, Osijek, Croatia \\ sdimter@gfos.hr \\ ** Faculty of Civil Engineering \\ University of Zagreb, Department of Transportation \\ Zagreb, Croatia \\ rukavina@grad.hr \\ vesnad@grad.hr
}

\begin{abstract}
A laboratory investigation of the properties of cement-stabilized pavement base course materials consisting of sand from the river Drava stabilized by hydraulic binder made of cement and fly ash is presented. The goal of the investigation was to determine the influence of several factors on the compressive and indirect tensile strengths. The factors included: a change in the structure of the stabilized mixes, a change in the treatment temperature and the time used in the sample treatment. The hydraulic binder was prepared using different percentages of fly ash in the binder: $0 \%$ (control mix), 25\%, 50\%, and $75 \%$. It was determined that the amount of fly ash strongly influences the strength of the stabilized mixes. Increasing the amount of fly ash in the binder leads to a decrease in the compressive and indirect tensile strengths.

KEYWORDS: Fly Ash Stabilized Mixes, Cement-Stabilized Base, Compressive Strength, Indirect Tensile Strength.
\end{abstract}

DOI:10.3166/RMPD.12.687-697 C 2011 Lavoisier, Paris 


\section{Introduction}

Stabilized mixes that are used in the construction of pavement base courses are mixes composed of aggregate bound with hydraulic binders or bitumen. Hydraulic binders used in stabilized mixes are industrial products such as Portland cement, metallurgic cement, and lime or by-products such as fly ash, slag, and cement kiln dust. Stabilized mixes with cement have been used most widely in pavement base courses for a number of years (Little et al., 2003).

Numerous researchers investigated the properties and behavior of cementstabilized mixes. Jones (1966), Sherwood (1968), Lister (1972) were among the first ones to carry measure the strength and elastic moduli. Good behavior of those layers under heavy traffic load was observed, as reported by Tayabji et al. (1982). Today, cement-stabilized base courses are represented in asphalt and concrete pavement structures.

Mixes stabilized with fly ash as an independent binder or a part of a binder started to be used in pavement structures somewhat later than cement mixes, in the 1970s (Bowen et al., 2000). The reasons for the selection of fly ash as a binder are numerous (Little et al., 2003). Fly ash has more or less expressed pozzolana capacities and forms a hard structure with free $\mathrm{CaO}$ and aggregate. The development of strength of such mixes continues over a longer period of time and results in higher strength values (Collins, 1985). The slow hydration of fly ash in combination with other binder reduces the heat and the tendency to crack. An important reason for use is also the cost-efficiency, considering that fly ash is a waste material.

Properties of stabilized mixes of natural aggregates with a binder composed of cement and fly ash were studied by Maher et al. (1993), Ksaibati et al. (1995), Bowen et al. (2000). The sustainable development concept, as well as the requirement for maximizing the application of waste materials, have resulted in a continuous increase in research of stabilized mixes in Europe and the World in which fly ash is an independent binder or is used in combination with cement.

In the Republic of Croatia, however, the situation with the use of fly ash is somewhat different. Consequently, fly ash was not used in civil engineering, and neither were conducted studies related to its possible use in pavement applications. The first study of mechanical properties of river sand, cement, and fly ash stabilized mixes in Croatia was conducted in 1996 (Dimter, 1996). Continued research (Dimter, 2005) stabilized mixes of river sand, cement and fly ash included examination of physical characteristics, strength and elastic properties of stabilized mixes.

Only part of the results, the results of compressive and indirect tensile strength of stabilized mixes, are presented in this paper and more detailed information are found in Dimter (2005). 


\section{Study objective}

The goal of the investigation was to determine the effect of the percentage of fly ash in a stabilized mix on the strength under various conditions and treatment times. For study purposes, stabilized mixes consisting of fine sand from the Drava river and a binder composed of cement and fly ash were designed. This sand is inexpensive local material, embedded in large amounts in structures, pavements and road embankments. Experience from previous use as a mechanically compacted and cement stabilized materials, are very positive. For reasons of broad application sand and insight into the similar research abroad, the determination of mineralogical composition of sand is not included in this study.

Fly ash used in this investigation does not have the capacity of independent binding and belongs to the group of alumina-silicate fly ash (HRN EN 142277-4, 2004). The share of fly ash in the binder was selected on the basis of cost-efficiency, given that the material at issue is a waste material, i.e. a cheaper binder. In addition, the designed binder composition was intended to cover a larger area of mixes, thus obtaining results consistent with the needs and requirements of specific road elements (pavement structure, subgrade, embankments and foundation soil).

\section{Study description}

Strengths of stabilized mixes are defined by compressive and tensile strengths. Compressive strength is defined by Croatian standard HRN U.B1.030 (ASTM D 2166-00) as an average stress in the sample exposed to uniaxial pressure due to a force causing the stress fracture. The indirect method was selected to determine the tensile strength of stabilized mixes in this study (HRN EN 12390-6:2001). The need for tensile strength testing arises from the following reason. Under the influence of traffic load, tensile stresses appear in the lower side of the cement-stabilized base layers. When this stresses exceed the tensile strength of the material, the layer fractures. Since the pavement structure in exploitation is permanently exposed to the effects of temperature and humidity variation, a more comprehensive insight into the properties of stabilized mixes requires knowledge of the behavior of those properties at various temperatures. For this reason, the testing was performed on samples treatment at four different temperatures: $5^{\circ} \mathrm{C}, 15^{\circ} \mathrm{C}, 25^{\circ} \mathrm{C}$, and $35^{\circ} \mathrm{C}$, with a humidity of $80 \%$. The tests were carried out on samples treated $7,28,180$, and 365 days.

\subsection{The aggregate and binder properties}

The basic aggregate used was sand from the Drava river. This is a local material of uniform granulometric composition with a grain size $\mathrm{D}_{50}=0.3 \mathrm{~mm}$, of grey-brown color, with a degree of non-uniformity $\mathrm{U}=\mathrm{d}_{60} / \mathrm{d}_{10}=2$ and Californian Bearing Ratio 
$(\mathrm{CBR})=8-12 \%$. The hydraulic binder was composed of cement (CEM II/B-M (P-S) $32.5 \mathrm{~N}$ ) and fly ash. The fly ash belongs to the silicate fly ash group. This means that, due to a low share of $\mathrm{CaO}$ (mass. 2.5\%) it does not have independent binding ability, but may be used only in combination with another hydraulic binder. Chemical composition of the fly ash is shown by mass portion of individual components (mass.\%): $\quad \mathrm{SiO}_{2}=53.00, \quad \mathrm{Al}_{2} \mathrm{O}_{3}=29.00, \quad \mathrm{Fe}_{2} \mathrm{O}_{3}=10.00, \quad \mathrm{CaO}=2.50, \quad \mathrm{SO}_{3}=0.70$, $\mathrm{MgO}=1.50$. The grain size distributions for fly ash and river sand are presented in Figure 1.

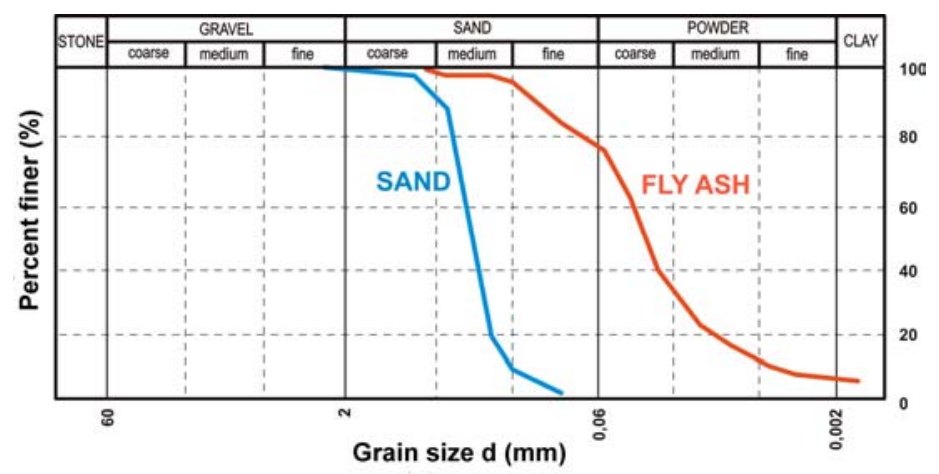

Figure 1. Grain size distributions for the drava river sand and fly ash

\subsection{Sample preparation and treatment procedure}

Based on the results of the preliminary tests detailed described in Dimter (2005), the compaction energy $\mathrm{E}=1.0 \mathrm{MJ} / \mathrm{m}^{3}$ was selected for sample preparation, at which the maximum density $\gamma_{\mathrm{dmax}}=1.729 \mathrm{t} / \mathrm{m}^{3}$ is attained with an optimum moisture content $\mathrm{w}_{\mathrm{opt}}=12.6 \%$. The compositions of stabilized mixes are shown in Table 1. Mixes without fly ash, with only pure cement in binder (marked "A" mixes) were control.

The samples were prepared in cylindrical moulds of a $10.0 \mathrm{~cm}$ diameter and 20.0 $\mathrm{cm}$ height. They were compacted manually by a Proctor compactor in five equal layers, with 46 hits per layer. After the preparation, the samples were extruded from the mould by means of a hydraulic press and left for a day at a room temperature $+20^{\circ} \mathrm{C}$ to dry. Then samples were placed in four climate chambers with temperatures of $5^{\circ}, 15^{\circ}, 25^{\circ}$, and $35^{\circ} \mathrm{C}$, and a humidity of $80 \%$. The climate chambers were equipped with humidifiers and sensors to keep requested humidity and heating/cooling units with thermostats to keep requested temperature. The samples were treated for 7, 28, 180, and 365 days, before strength testing. For each set of treatment conditions, tests were carried out on two identical samples of stabilized mixes. 
Table 1. Composition of the mixes

\begin{tabular}{|c|c|c|c|c|}
\hline \multirow{2}{*}{$\begin{array}{c}\text { Stabilized } \\
\text { mixes }\end{array}$} & \multirow{2}{*}{$\begin{array}{c}\text { Amount of the binder } \\
\text { \% of the total sand mass })\end{array}$} & \multicolumn{2}{|c|}{$\begin{array}{c}\text { Composition } \\
\text { of the binder }\end{array}$} & \\
\cline { 3 - 5 } & & \% cement & $\%$ fly ash & \\
\hline I A & 10 & 100 & 0 & Control mix \\
\hline I B & 10 & 75 & 25 & \\
\hline I C & 10 & 50 & 50 & \\
\hline I D & 10 & 25 & 75 & \\
\hline II A & 14 & 100 & 0 & Control mix \\
\hline II B & 14 & 75 & 25 & \\
\hline II C & 14 & 50 & 50 & \\
\hline II D & 14 & 25 & 75 & \\
\hline
\end{tabular}

\section{Strength test results and discussion}

Details about determining compressive and indirect tensile strength of a stabilized mixes can be found in the Appendix.

\subsection{Compressive strength}

The following sections present the results of the effect of the percentage of fly ash, as well as the temperature and treatment time, on compressive and indirect tensile strengths of the mixes. Compressive and tensile strengths are presented in their absolute amounts. In cases where the results indicated a very clear correlation between some of the study parameters, the results were presented by the normalized strength values. Impact of fly ash content on mixes compressive strength (for mixes with $14 \%$ binder, group II) is illustrated in the diagrams in Figure 2.

The impact of the fly ash percentage in the binder on the compressive strength of stabilized mixes is significant. Increase in the fly ash percentage, as a rule, decreases the compressive strength of stabilized mixes. A decrease in the compressive strength is more pronounced for the mixes with a $10 \%$ binder content (group I) than mixes with a $14 \%$ binder content (group II).

An average decrease in the compressive strength as the fly ash percentage in the binder increases, in comparison to the control mixture, ranges between $35 \%$ and $74 \%$ for all mixes and different temperatures and time of treatment. An average decrease in the strength of stabilized mixes for different treatment times is evident from the normalized diagrams in Figure 3. 

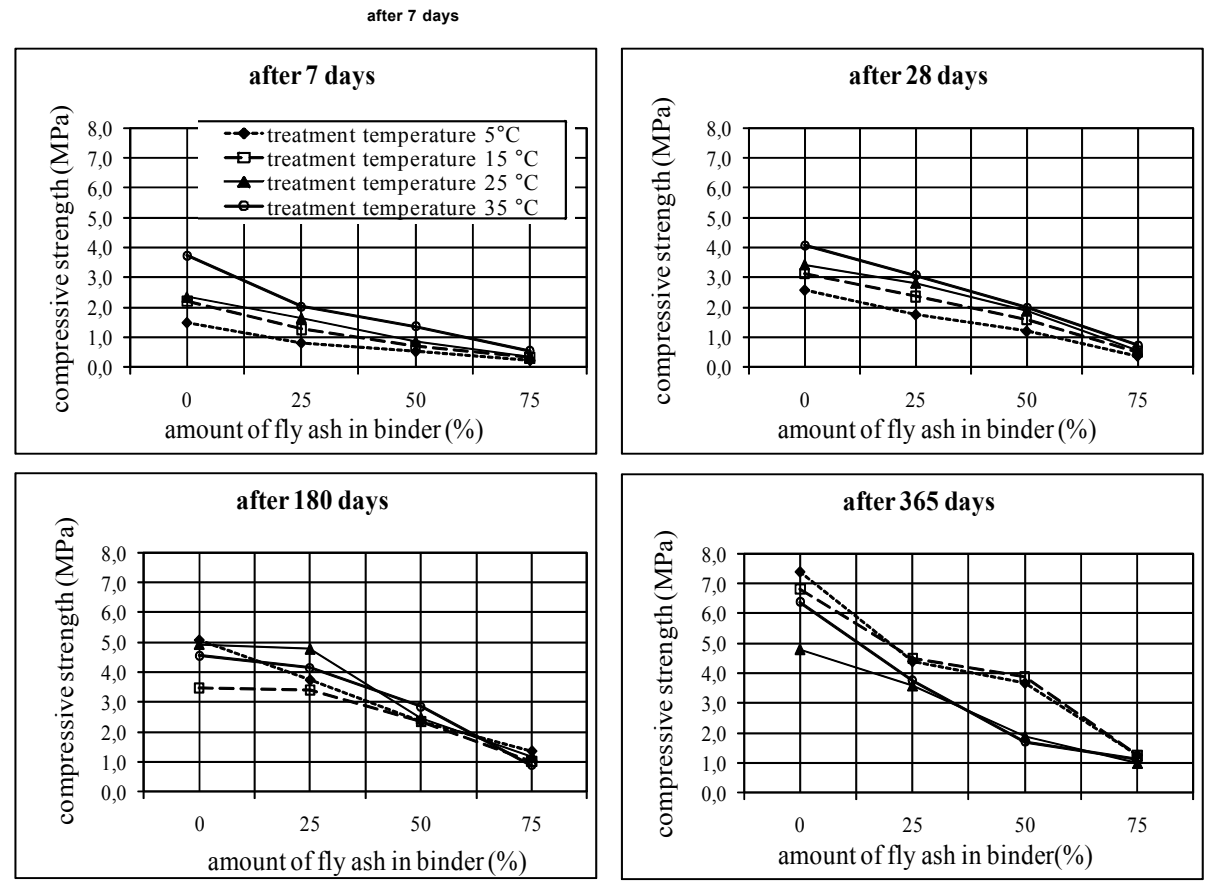

Figure 2. Effect of fly ash content on compressive strength (group II, 14\% binder)

An average decrease in the compressive strength as the fly ash percentage in the binder increases, in comparison to the control mixture, ranges between $35 \%$ and $74 \%$ for all mixes and different temperatures and time of treatment. An average decrease in the strength of stabilized mixes for different treatment times is evident from the normalized diagrams in Figure 3.
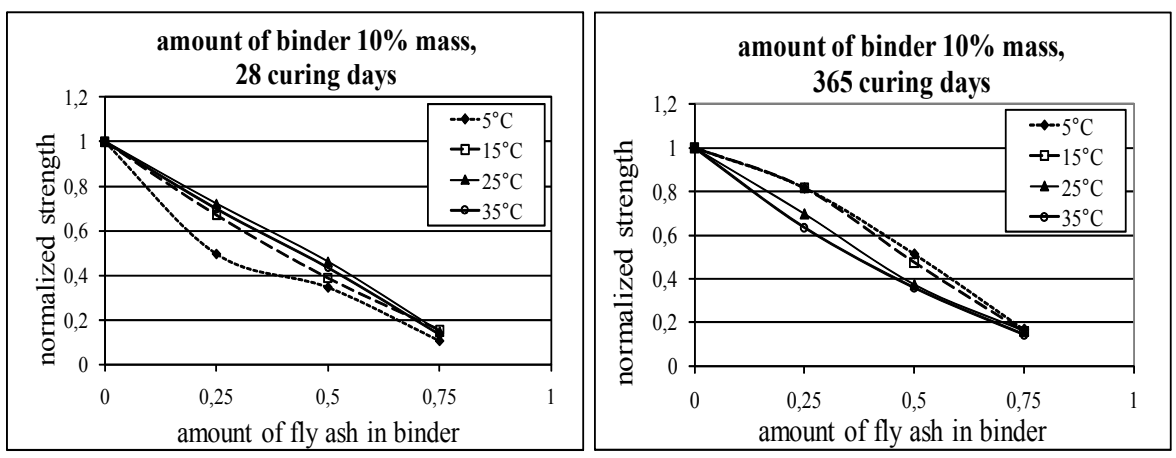

Figure 3. Normalized diagrams of compressive strengths 
It is a fact that an increase of the compressive strength of mixes with fly ash is slower than an increase of the compressive strength of mixes with pure cement. However, the increase of the compressive strength of the fly ash stabilized mixes is extended over a longer period of time. Since in this study some of the mixes had a very high percentage of fly ash in the binder, extended treatment of samples was a very significant factor in the strength development. Impact of the temperature and treatment time on compressive strength for mixes with amount of binder $14 \%$ mass. are illustrated in the diagrams in Figure 4.

Increase of the compressive strength is fast in the first 28 days, and it decelerates thereafter. The fastest increase in the compressive strength, in terms of the absolute value, is achieved for the mixes without fly ash (mixes A).

The effect of the treatment temperature on the development of compressive strength of stabilized mixes is significant. For samples with a treatment time of 7 and 28 days, an increase in the compressive strength with temperature is clearly visible. Stabilized mixes treated at lower temperatures develop compressive strength later, in comparison to the mixes treated at higher temperatures.

$$
\text { after } 7 \text { days }
$$
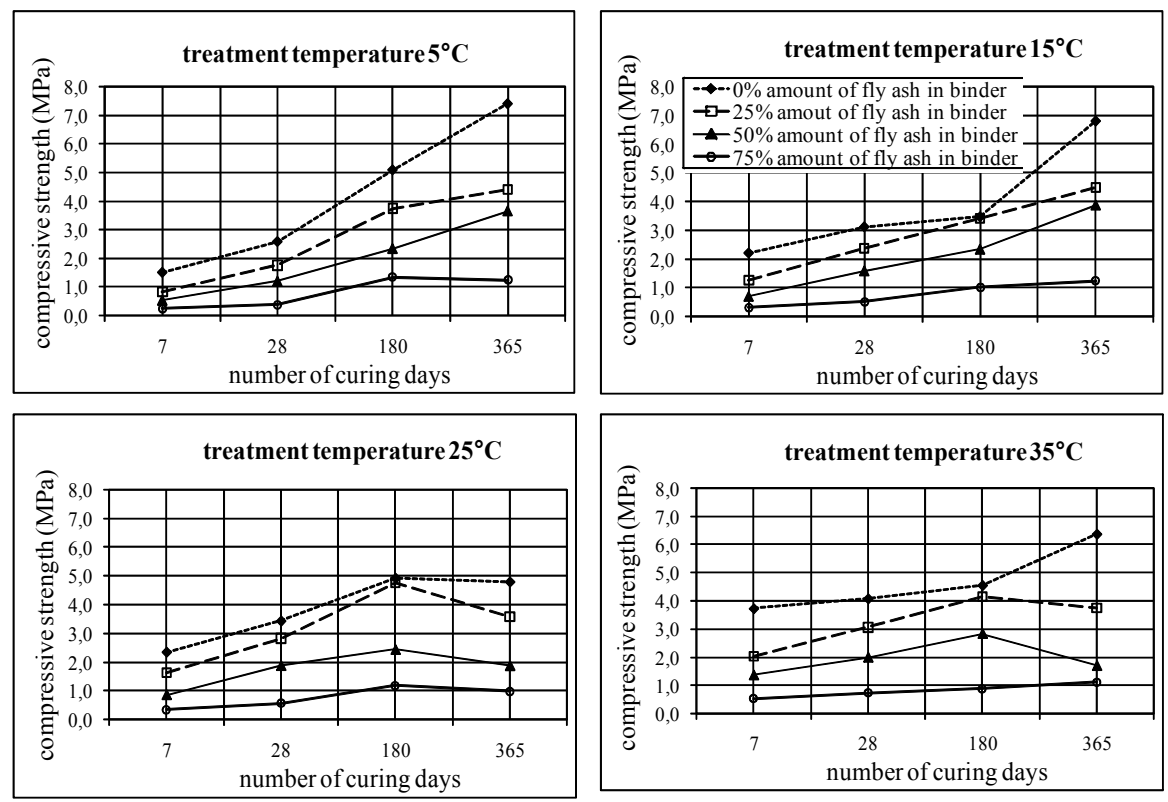

Figure 4. Effect of temperature and treatment time on compressive strength

For stabilized mixes with $75 \%$ of fly ash in the binder (mixes D), treatment temperature has a very small effect on the strength development. Few results of 
compressive strength after 180 days have no logical trend-there is no explanation except possible error in investigation.

The achieved results for compressive strength were compared to the required compressive strengths according to the Croatian standard HRN U.E9.024. It was established that the fly ash can replace a certain quantity of cement ( $\max 25 \%$ ) in binder, and that the compressive strength for stabilized mix stays within the prescribed limits. As such, the minimal quantity of binder in the stabilized mix must be limited to 12 mass \%. Results for weaker stabilized mix, with $50 \%$ and $75 \%$ of fly ash in the binder (mixes C and D), do not satisfy the conditions for the production of stabilized layers for roadway construction. Values for minimal compressive strength of these mixes are significantly lower than those required, however these stabilized mixes could be used for subgrades, construction of embankments or improving the foundation soil, where the quality requirements for materials used are lower (General technical conditions for roadwork, 2001).

\subsection{Indirect tensile strength}

Impact of fly ash on indirect tensile strength is illustrated in diagrams in Figure 5.
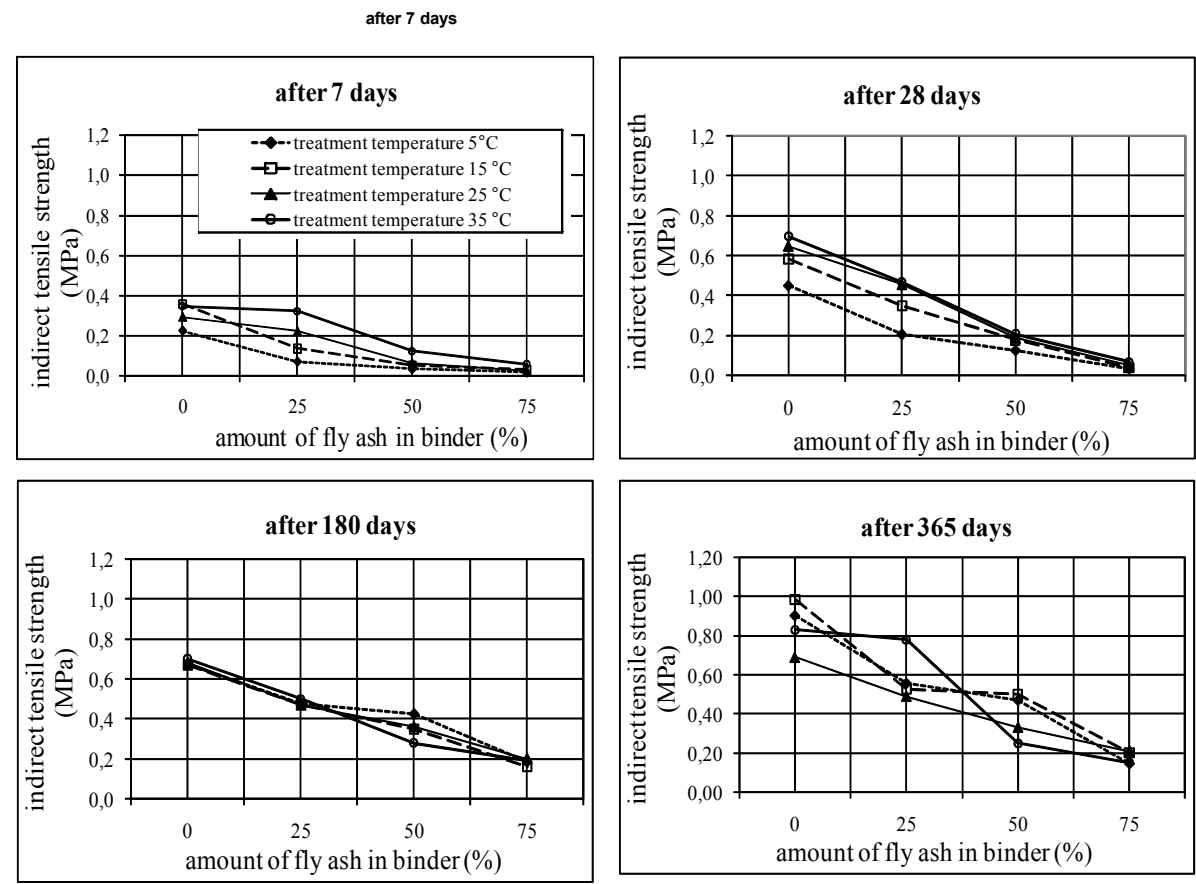

Figure 5. Effect of fly ash content on indirect tensile strength (14\% binder) 
Results of evaluation of indirect tensile strength indicated a similarity with the results of evaluation of the compressive strength of stabilized mixes:

An increase in the fly ash percentage in the binder, as a rule, reduces the indirect tensile strength of stabilized mixes. An average reduction of the indirect tensile strength with an increase in the fly ash percentage in the binder for all mixes, all temperatures and treatment times is $46 \%-85 \%$. The highest values of the indirect tensile strength have stabilized mixes without fly ash (mixes A).

The effect of treatment temperature on the development of indirect tensile strength is considerable. For samples treated for 7 and 28 days, respectively, an increase in indirect tensile strength is directly dependent on temperature: the tensile strength increases with the treatment temperature. With extended treatment of samples those relations change, and mixes treated at lower temperatures develop a higher indirect tensile strength at a later stage.

Indirect tensile strength of stabilized mixes increases with treatment time. The increase is most prominent in the initial period of up to 28 days; thereafter the development of indirect tensile strength slows down. The higher the fly ash percentage in the binder, the lower the increase in the indirect tensile strength. Based on the comparison of the absolute values, mixes without fly ash (mixes A) have the fastest increase in the tensile strength.

For samples treated up to 28 days, increase in the tensile strength is directly dependent on the temperature. Stabilized mixes treated at lower temperatures develop higher strength later. Similar to the results for compressive strength, for stabilized mixes D with $75 \%$ of fly ash in the binder, the treatment temperature has a very low effect on the development of indirect tensile strength.

\section{Conclusions}

The comparison of the strength results of stabilized mixes leads to the following conclusions:

1) The effect of the percentage of fly ash in a binder on compressive and indirect tensile strengths of stabilized mixes is significant: An increase in the fly ash percentage in the binder results in a decrease of both compressive and indirect tensile strengths. Based on the absolute strength, the higher the fly ash percentage in the binder, the lower the strength increase.

2) The impact of treatment temperature on the development of both strengths is significant. The lower treatment temperatures are more beneficiary for the development of strengths during long treatment of samples, since they enable a gradual increase of strengths, which finally results in their maximal values.

3) The obtained results indicate the inertness of fly ash used in this study, given that a small share of $\mathrm{CaO}$ in fly ash is by no means sufficient for the development of 
a late pozzolana reaction. By comparison of achieved results for compressive strengths with the Croatian standards HRN U.E9.024, it was established that to a certain extent, fly ash can replace a certain quantity of cement ( $\max 25 \%$ ) in binder, with compressive strength of the stabilized mix staying within the prescribed limits. For that, the minimal quantity of binder in the stabilized mix must be limited to 12 mass $\%$. Also, there is a benefit: The slow hydration of fly ash in combination with cement will reduce the heat and the tendency to crack of layers.

The results of this study represent significant stimulation for the possible use of such non-traditional binders with local materials, which have both technical and economical justification in the production of stabilized mixes in road construction.

\section{Bibliography}

ASTM D 2166-00 Unconfined compressive strength (HRN U.B1.030:1968)

Bowen M.M., Ksaibati K., Performance Evaluation of Cement-Treated Roadway Bases, University of Wyoming, Laramie, WY, November 2000.

Collins R., Fly ash in bases and subbases, Proceedings: Fly ash in Highway Construction, Seminar FHWA, Washington, 1985.

Dimter S., Stabilising Effects of Fly Ash on Local Materials, master thesis, Faculty of Civil Engineering, University in Zagreb, Zagreb, (original in Croatian), 1996.

Dimter S., Properties of Stabilized Mixes for Road Building Purposes, Ph.D. Dissertation, University in Zagreb, Faculty of Civil Engineering (original in Croatian), 2005.

General technical conditions for roadwork, II Earthworks, drainage, supporting and lining walls, Croatian Roads - Croatian Motorways, Zagreb, 2001, p. 47-53

HRN EN 14227-4 Hydraulically bound mixtures-Specifications-part 4: Fly ash for hydraulically bound mixtures, 2004.

HRN EN 12390-6 Tensile splitting strength of test specimens, 2001

HRN U.E9.024 Construction of bearing layers of roadway constructions for roads, from materials stabilised with cement or similar hydraulic bindings

Jones R., Measurement of Elastic and Strength Properties of Cemented Materials in Road Bases, Highway Research Record 128, 1966, p. 101-111.

Ksaibati K., Conklin T., "Field Performance of Cement-Treated Bases With and Without Fly Ash", Transportation Research Record, No. 1440, Transportation Research Board, 1995.

Little D., Males E., Prusinski J., Stewart B., "Cementitious Stabilization, Transportation in the New Millennium”, Transportation Research Board, Washington, 2003, p. 1-7.

Lister N.W., "Design and Performance of Cement Bound Bases", The Journal of the Institution of Highway Engineers 14, 1972, p. 21-33. 
Maher M.H., Balaguru P.N., "Properties of Flowable High-Volume Fly Ash-Cement Composite", Journal of Materials in Civil Engineering, Vol. 5, No. 2, 1993, p. 212-225.

Sherwood P.T., "The properties of Cement Stabilized Materials”, Road Research Laboratory, RRL Report LR205, 1968.

Tayabji S.D., Nussbaum P.J., Ciolko A.T., "Evaluation of Heavily Loaded Cement-Stabilized Bases", Transportation Research Record 839, TRB, Washington, D.C., 1982, p. 6-11.

\section{Strength testing procedures}

\section{Compressive strength}

Cement-stabilized materials are usually tested for compressive strength after 7 and 28 days of treatment, respectively. However, for materials with extended time of binding, such as fly ash, the time period for attaining the desired compressive strength may also be longer. Compressive strength of stabilized mixes depends both on material properties and on treatment conditions, and is determined as an average stress in the sample exposed to uniaxial pressure due to a force causing the stress fracture (HRN U.B1.030, ASTM D 2166-00). The compressive strength was calculated using the formula:

$$
f_{c}=\frac{P}{A}
$$

Where: $\mathrm{f}_{\mathrm{c}}=$ compressive strength $(\mathrm{MPa}) ; \mathrm{P}=\max$ compressive force $(\mathrm{MN}) ; \mathrm{A}=$ sample cross section area $\left(\mathrm{m}^{2}\right)$.

\section{Indirect tensile strength}

Evaluation of the tensile strength of cement-stabilized materials is more complex than of the compressive strength. The tensile strength in this study was determined by the indirect test method (HRN EN 12390-6) considered the most appropriate for practical testing of cement-stabilized materials. In this method, loading is applied on a cylindrical sample via loading bar. Such a load causes a relatively uniform strain perpendicular to the diameter plane at which the pressure is applied.

The indirect tensile strength was computed according to:

$$
f_{t}=\frac{2 P}{\pi t d}
$$

Where: $\mathrm{f}_{\mathrm{t}}=$ indirect tensile strength $(\mathrm{MPa}) ; \mathrm{P}=\max$ compressive force $(\mathrm{MN})$; $\mathrm{t}=$ length of the sample $(\mathrm{m}) ; \mathrm{d}=$ diameter of the sample $(\mathrm{m})$.

Received: 12 April 2011

Accepted: 11 November 2011 